\title{
State Regulations Promoting Infant Physical Activity in Early Care and Education
}

\author{
Sara E. Benjamin-Neelon, PhD, JD, Brian Neelon, PhD, John Pearce, PhD, \\ Elyse R. Grossman, PhD, JD,' Sarah Gonzalez-Nahm, PhD, MPH, RD, \\ Meghan Slining, PhD, $\mathrm{MPH}^{3}$, Kiyah Duffey, $\mathrm{PhD}^{4}$, and Natasha Frost, JD ${ }^{5}$
}

\section{Abstract}

Background: State policies have the potential to improve early care and education (ECE) settings, but little is known about the extent to which states are updating their licensing and administrative regulations, especially in response to national calls to action. In 2013, we assessed state regulations promoting infant physical activity in ECE and compared them with national recommendations. To assess change over time, we conducted this review again in 2018.

Methods: We reviewed regulations for all US states for child care centers (centers) and family child care homes (homes) and compared them with three national recommendations: (1) provide daily tummy time; (2) use cribs, car seats, and high chairs for their primary purpose; and (3) limit the use of restrictive equipment (e.g., strollers). We performed exact McNemar's tests to compare the number of states meeting recommendations from 2013 to 2018 to evaluate whether states had made changes over this period.

Results: From 2013 to 2018, we observed significant improvement in one recommendation for homes - to use cribs, car seats, and high chairs for their primary purpose (odds ratio $11.0 ; 95 \%$ CI $1.6-47.3 ; p=0.006$ ). We did not observe any other significant difference between 2013 and 2018 regulations.

Conclusions: Despite increased awareness of the importance of early-life physical activity, we observed only modest improvement in the number of states meeting infant physical activity recommendations over the past 5 years. In practice, ECE programs may be promoting infant physical activity, but may not be required to do so through state regulations.

Keywords: child care; physical activity; policy; regulation; tummy time

\section{Introduction}

$\mathbf{R}$ ecent calls to action highlight the importance of promoting physical activity and decreasing sedentary time for very young children. ${ }^{1-5}$ A small but growing body of evidence suggests that physical activity during the first year of life has important biological and behavioral health implications. ${ }^{6-8}$ Moreover, a recent systematic review found evidence of tracking of physical activity within early childhood (birth to 5 years) and from early to middle childhood. ${ }^{6}$ Thus, promoting physical activity and decreasing sedentary time in infancy appear critically important for later health. However, few studies have mea- sured physical activity and inactivity in infants. ${ }^{8-10}$ Based on available evidence, infants may not be achieving recommended levels of physical activity. A study from Australia found that the majority of infants assessed did not meet current 24-hour movement guidelines. ${ }^{11}$ In particular, few infants were provided with sufficient tummy time by parents and other caregivers and approximately half of infants spent excessive time in confining equipment, such as strollers, car seats, and swings. ${ }^{11}$ Furthermore, in a study of young children from Canada that included a small sample of infants, few met physical activity guidelines and the majority were sedentary for a large percentage of waking hours. $^{12}$

\footnotetext{
'Department of Health, Behavior, and Society, Johns Hopkins Bloomberg School of Public Health, Baltimore, MD.

${ }^{2}$ Department of Public Health Sciences, Medical University of South Carolina, Charleston, SC.

${ }^{3}$ Department of Health Sciences, Furman University, Greenville, SC.

${ }^{4}$ Kiyah Duffey Consulting, Inc., Blacksburg, VA.

${ }^{5}$ Public Health Law Center, Mitchell Hamline School of Law, St Paul, MN.
} 
Parents and other caregivers can promote physical activity and limit inactivity in infants by providing daily tummy time for younger infants, allowing infants to move freely on the ground, and limiting time spent in restrictive equipment. It is important to provide opportunities for physical activity for infants at home and in other settings where infants spend time. Out-of-home child care for young children has become more prevalent in recent years, and parents now share the caregiving responsibility with other adults. In developed countries, approximately onequarter of children younger than 3 years spent time in early care and education (ECE) settings. ${ }^{13}$ Among infants in the United States, nearly $16 \%$ spent time in more formal child care facilities and $\sim 35 \%$ were cared for in less formal arrangements. ${ }^{14}$ Thus, ECE settings have become important targets for obesity prevention through the promotion of physical activity and the reduction of sedentary time. ${ }^{1-3,5}$

In 2013, we conducted a review of state licensing and administrative regulations for ECE related to infant physical activity and compared them with national recommendations. ${ }^{15} \mathrm{We}$ found that the majority of states lacked regulations consistent with the recommendations and that this was especially true for family child care homes. Since our prior review, more than two-thirds of states have updated their regulations. Thus, we were interested in assessing whether states had made changes to their regulations related to infant physical activity. We hypothesized that more states would have regulations consistent with national recommendations due to growing attention to the issue of earlylife obesity prevention and the promotion of physical activity during infancy. Therefore, the purpose of this study was to assess current infant physical activity regulations for ECE facilities, compare them with national recommendations, and evaluate the extent to which states have enacted new regulations over the past 5 years, since our prior review. We also aimed to display our findings graphically to allow for better visualization of states with and without regulations meeting the national recommendations.

\section{Methods}

\section{Infant Physical Activity Recommendations}

The infant physical activity recommendations were put forth in Early Childhood Obesity Prevention Policies by the National Academies of Sciences, Engineering, and Medicine (formerly the Institute of Medicine) in 2011 as recommended actions for states interested in enhancing their regulations. ${ }^{1}$ These recommendations encouraged ECE providers to (1) provide daily tummy time (in the prone position) for infants younger than 6 months; (2) use cribs, car seats, and high chairs for their primary purpose - cribs for sleeping, car seats for vehicle travel, and high chairs for eating); and (3) limit the use of restrictive equipment such as strollers, swings, and bouncer seats/chairs for holding infants while awake. States were encouraged to consider these recommendations when enacting new regulations but were not required to do so. We conducted a review of state regulations following the release of these recommendations. ${ }^{15}$ Our current review serves as an update, documenting regulations that have been enacted within the past 5 years, since our prior review.

\section{Review of Regulations}

For this cross-sectional study, we reviewed state regulations for ECE facilities current as of May 31, 2018. We obtained regulations for all 50 US states and the District of Columbia from the National Database of Child Care Licensing Regulations maintained on a publicly available website by the US Department of Health and Human Services. ${ }^{16}$ Two independent reviewers coded each state's regulations to assess consistency with the recommendations using a combination of keyword searches and review of the full regulations text. Regulations needed to include specific language embodying the spirit of each recommendation. Percent agreement between the two reviewers was $98 \%$ (provide daily tummy time), $67 \%$ (use cribs, car seats, and high chairs for their primary purpose), and $83 \%$ (limit the use of restrictive equipment). We reconciled differences through a collective research team discussion until both reviewers and the principal investigator were all in agreement.

We reviewed regulations for the main types of child care facilities, child care centers (centers) and family child care homes (homes), consistent with prior ECE regulatory reviews. ${ }^{15,17-23}$ Typically, states have separate regulations for centers and homes, although in some instances the same set of regulations governs both types of facilities. Generally, centers have a greater number of staff members, care for more children, and are located in a separate, dedicated building. Family child care homes typically include one provider, who is often the owner, with fewer children. As we did for our prior studies, ${ }^{15,17,24,25}$ we grouped subcategories of facilities into either centers or homes for the purpose of this review. This categorization is especially important, as centers and homes represent two distinct types of ECE settings and the enactment of new regulations often varies substantially between centers and homes. Ethical approval was not required by the Johns Hopkins Bloomberg School of Public Health as human subjects were not included in this regulations review.

\section{Analysis}

We calculated the number of regulations consistent with each of the three infant physical activity recommendations by state and ECE facility type. We then performed exact McNemar's tests to compare the number of states meeting recommendations in 2013 with 2018 for both centers and homes. We present results in terms of odds ratios, $95 \% \mathrm{CI}$, and two-sided $p$-values. We conducted all analyses using SAS 9.4 (SAS Institute, Inc., Cary, NC), with a significance level of $\alpha=0.05$. Next, to graphically display our results, we used ArcGIS (ArcGIS 10; ESRI, Inc., Redlands, CA) to map the number of regulations consistent with each 
Table I. State Licensing and Administrative Regulations Consistent with Infant Physical Activity Recommendations in 2018

\begin{tabular}{|c|c|c|}
\hline & Child care centers & Family child care homes \\
\hline $\begin{array}{l}\text { Provide daily tummy time } \\
\text { for infants younger than } 6 \text { months }\end{array}$ & $\begin{array}{l}\text { Alabama, Arizona, Colorado, Connecticut, } \\
\text { Delaware, District of Columbia, Georgia, Illinois, } \\
\text { New Jersey, New York, North Carolina, Oklahoma, } \\
\text { Virginia, Washington, West Virginia, Wisconsin }\end{array}$ & $\begin{array}{l}\text { Alabama, Colorado, Connecticut, District } \\
\text { of Columbia, Georgia, Illinois, New Jersey, } \\
\text { New York, North Carolina, Washington }\end{array}$ \\
\hline $\begin{array}{l}\text { Use cribs, car seats, and high chairs } \\
\text { for their primary purpose }\end{array}$ & $\begin{array}{l}\text { Alaska, Arizona, Arkansas, Colorado, District of } \\
\text { Columbia, Florida, Georgia, Illinois, Indiana, lowa, } \\
\text { Kansas, Kentucky, Louisiana, Michigan, Minnesota, } \\
\text { Mississippi, Missouri, Montana, Nevada, New } \\
\text { Mexico, New York, North Dakota, Ohio, } \\
\text { Oklahoma, Oregon, Rhode Island, South Carolina, } \\
\text { Texas, Utah, Washington, West Virginia }\end{array}$ & $\begin{array}{l}\text { Alaska, Arizona, Arkansas, Colorado, Delaware, } \\
\text { District of Columbia, Georgia, Illinois, lowa, } \\
\text { Kansas, Kentucky, Michigan, Mississippi, Missouri, } \\
\text { Montana, Nevada, New Jersey, New Mexico, } \\
\text { New York, North Dakota, Ohio, Oregon, Rhode } \\
\text { Island, South Carolina, Tennessee, Texas, Utah, } \\
\text { Virginia, Washington, West Virginia }\end{array}$ \\
\hline $\begin{array}{l}\text { Limit use of restrictive equipment } \\
\text { for holding infants while awake }\end{array}$ & $\begin{array}{l}\text { Alaska, Arizona, Arkansas, Colorado, District } \\
\text { of Columbia, Georgia, Indiana, lowa, Kansas, } \\
\text { Louisiana, Maine, Maryland, Massachusetts, } \\
\text { Michigan, Minnesota, Mississippi, Missouri, } \\
\text { Montana, Nevada, New Hampshire, New Jersey, } \\
\text { New Mexico, New York, Ohio, Oklahoma, Rhode } \\
\text { Island, South Carolina, Tennessee, Texas, Utah, } \\
\text { Vermont, Washington, West Virginia }\end{array}$ & $\begin{array}{l}\text { Alaska, Arizona, Colorado, Delaware, District } \\
\text { of Columbia, Georgia, Illinois, lowa, Maryland, } \\
\text { Montana, Nevada, New Hampshire, New Jersey, } \\
\text { New Mexico, New York, Ohio, Oklahoma, } \\
\text { Oregon, Rhode Island, South Carolina, } \\
\text { Tennessee, Texas, Utah, Vermont, Virginia, } \\
\text { West Virginia }\end{array}$ \\
\hline
\end{tabular}

recommendation for centers and homes between 2013 and 2018. Visual depiction allows for a relatively quick assessment of change over time and facilitates an at-a-glance comparison of states with their neighbors.

\section{Results}

\section{Overview}

Since our prior review in 2013, 38 states updated their regulations for centers and 34 states updated their regulations for homes. South Carolina and Arizona had the oldest regulations, updated last in 2005 and 2007, respectively. A small number of states had regulations for centers consistent with all three recommendations, including Arizona, Colorado, the District of Columbia, Georgia, New York, Oklahoma, Washington, and West Virginia (Table 1). Colorado, the District of Columbia, Georgia, Illinois, New Jersey, and New York were the only states with regulations for homes consistent with all three of the recommendations. From 2013 to 2018, we observed significant improvements in one recommendation for homes - to use cribs, car seats, and high chairs for their primary purpose (odds ratio $11.0 ; 95 \%$ CI $1.6-47.3 ; p=0.006$ ) (Table 2). There were no significant improvements for the other recommendations for centers or homes. Results are displayed in the 2013 and 2018 maps presented in Figure 1.

\section{Provide Daily Tummy Time for Infants Younger Than 6 Months}

In 2013, 11 states had regulations requiring centers to provide daily tummy time for infants younger than 6 months; this increased to 16 states in 2018. For homes, the number of states with regulations requiring tummy time increased from 9 to 10 from 2013 to 2018 , although one state removed the regulation and another added the regulation. Some states required a minimum number of minutes of tummy time each day or multiple times per day. New Jersey regulations for centers, for example, provided, "[s]taff members shall ensure infants have age-appropriate, supervised tummy time at least twice per day." Virginia regulations for homes provided, "[i]nfants, who cannot turn themselves over and are awake, shall be placed on their stomachs a total of 30 minutes each day to facilitate upper body strength and to address misshapen head concerns."

\section{Use Cribs, Car Seats, and High Chairs for Their Primary Purpose}

In our prior review, 24 states required centers to use cribs, car seats, and high chairs for their primary purpose only, compared with 31 states in 2018. Homes also improved in the number of states with regulations consistent with this recommendation, increasing from 20 in 2013 to 30 in 2018. For example, New York regulations for centers provide, "[c] hildren may not sleep or nap in car seats, baby swings, strollers, infant seats, or bouncy seats. Should a child fall asleep in one of these devices, he or she must be moved to a crib/cot or other approved sleeping surface." Mississippi regulations for both centers and homes are nearly identical to the language of the recommendation in that they provide, "[c]ribs, car seats, and high chairs are to be used only for their primary purpose, i.e., cribs for 


\begin{tabular}{|c|c|c|c|c|}
\hline & \multicolumn{2}{|c|}{ Child care centers } & \multicolumn{2}{|c|}{ Family child care homes } \\
\hline & Odds ratio $(95 \% \mathrm{Cl})$ & $p$ & Odds ratio $(95 \% \mathrm{Cl})$ & $p$ \\
\hline Provide daily tummy time for infants younger than 6 months & $6.0(0.7-276.0)$ & 0.13 & $1.3(0.2-7.5)$ & 1.00 \\
\hline Use cribs, car seats, and high chairs for their primary purpose & $3.3(0.9-18.8)$ & 0.09 & $11.0(1.6-47.3)$ & 0.006 \\
\hline Limit use of restrictive equipment for holding infants while awake & $2.0(0.5-9.1)$ & 0.55 & $2.0(0.4-12.4)$ & 0.51 \\
\hline
\end{tabular}

$\mathrm{Cl}$, confidence intervals.

sleeping, car seats for vehicle travel, and high chairs for eating."

\section{Limit the Use of Restrictive Equipment}

\section{for Holding Infants While Awake}

For centers, 29 states limited the use of restrictive equipment in 2013, compared with 33 in 2018. For homes, the number of states with this regulation increased from 23 to 26. Regulations for Mississippi homes mirror the recommendation and provide, "[p]roviders should limit the use of equipment such as strollers, swings, and bouncer seats/chairs for holding infants while they are awake." About half of states include a time limit for infants in restrictive equipment. Colorado regulations for homes, for example, provide, "[c]hildren must not be confined for prolonged periods of time to cribs, playpens, swings, high chairs, infant seats, or other equipment that confines movement. They must have an opportunity each day for freedom of movement, such as creeping, crawling, or walking in a safe, clean, open, uncluttered area. Children who are awake must not be confined for more than fifteen (15) minutes at a time to cribs, playpens, swings, high chairs, infant seats, or other equipment that inhibits freedom of movement. Children who are actively eating may be in a high chair or other approved feeding equipment for longer than fifteen (15) minutes. Children must be moved away from the feeding location once feeding is complete." Similarly, Delaware regulations for homes provide, "[a] licensee shall ensure children are not in cribs, packn-plays, swings, high chairs, seats, or stationary activity centers for more than 30 minutes at a time while awake. Toddlers and infants, as appropriate, shall be provided with an activity during this time. After removing the child from the equipment, children shall be able to move freely on the floor."

\section{Discussion}

We observed only modest improvement in state regulations for the three infant physical activity recommendations examined. States significantly increased the number of regulations targeting homes that were consistent with the recommendation to use cribs, car seats, and high chairs for their primary purpose only from 2013 to 2018. In addition, when we considered regulations consistent with all three recommendations collectively, states appeared to make substantial improvement for regulations governing homes over time. However, we did not observe any significant changes in state regulations for centers for any of the physical activity recommendations. Although we observed few changes states made for regulations targeting centers, states may be in the process of updating their regulations at any given time. Therefore, it is useful to conduct assessments periodically to assess change over time.

Previous reviews have found that states varied widely in their regulations related to children's physical activity. ${ }^{15,18,19,26}$ However, these cross-sectional regulatory reviews are limited in their ability to provide information about actual practice in ECE. Two prior studies have prospectively assessed compliance with new state physical activity policies targeting preschoolers (one a state regulation and the other a mandatory state standard) and found some improvement. ${ }^{27,28}$ State regulations have the potential to impact physical activity practices, although more evidence is needed demonstrating the effectiveness of new regulations - especially for infants.

We did not see much improvement in the number of states with regulations related to tummy time, despite recent research and practice recommendations to offer tummy time for infants younger than 6 months at least daily. Tummy time provides infants with supervised time spent on their stomachs in the prone position and has demonstrated positive effects on infant physical and behavioral development. ${ }^{29-31} \mathrm{~A}$ recent review of correlates of tummy time reviewed 15 studies from seven countries; not surprisingly, tummy time was higher when parents and other caregivers prioritized time for infants to spend on the floor in the prone position. ${ }^{32}$ Another recent study assessed ECE provider adherence to tummy time and other infant physical activity recommendations in Australia, Canada, and the United States. The researchers found that ECE providers reported setting aside adequate tummy time for infants, but fewer reported limiting the use of restrictive equipment for infants in care. ${ }^{33}$ 
A
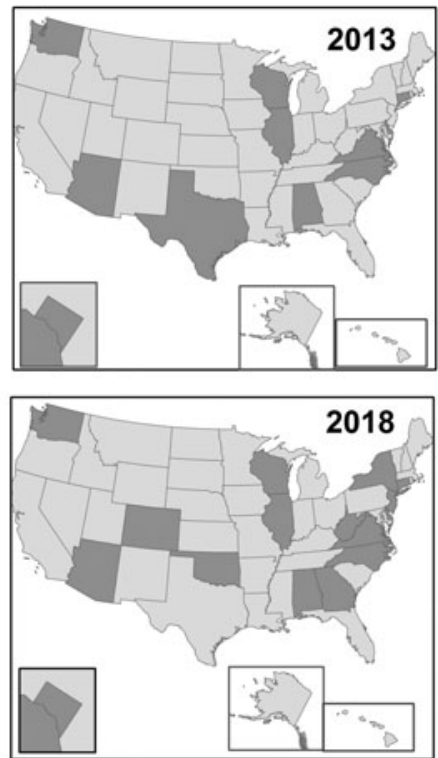

Provide daily tummy time for infants less than 6 months

\begin{tabular}{l|l} 
REG NO REG \\
\hline
\end{tabular}
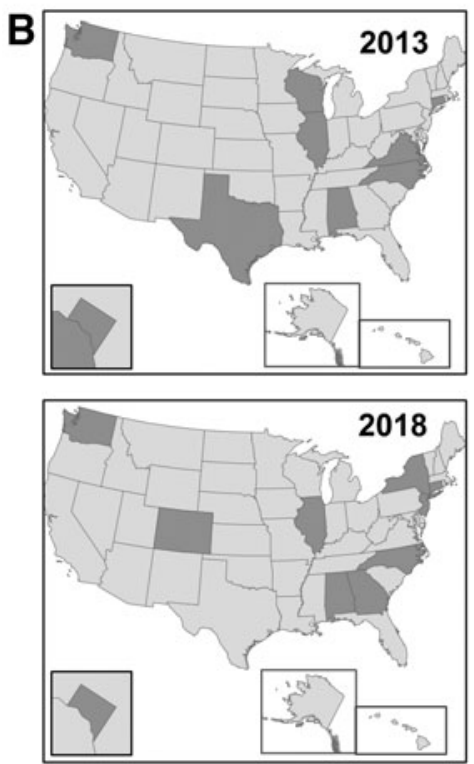

Provide daily tummy time for infants less than 6 months NO REG

REG
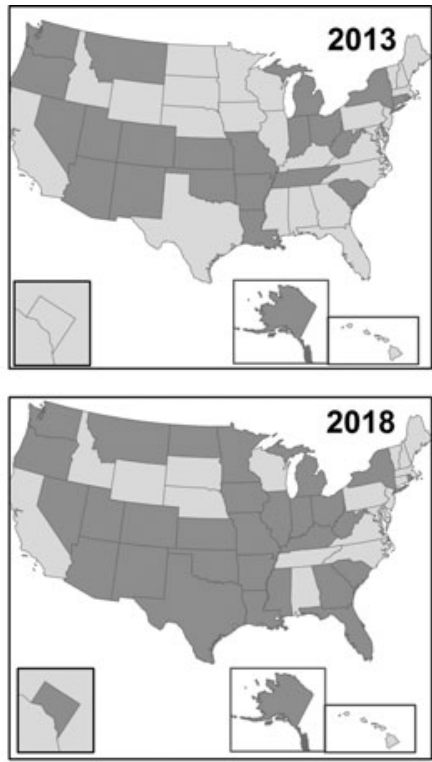

Use cribs, car seats, and highchairs for their primary purpose
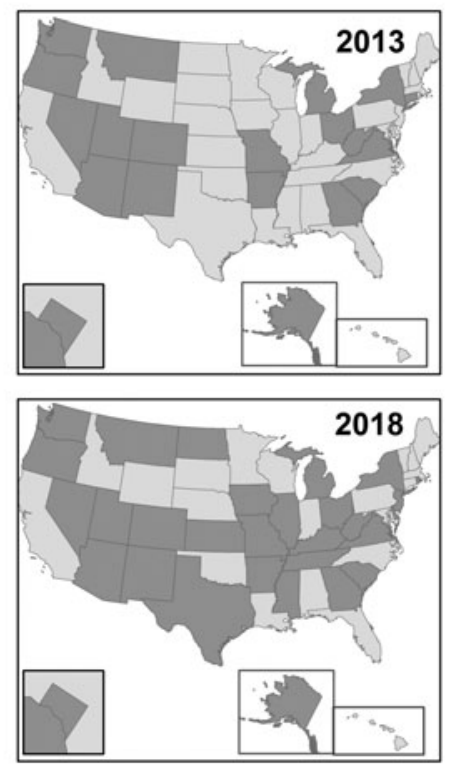

Use cribs, car seats, and highchairs for their primary purpose
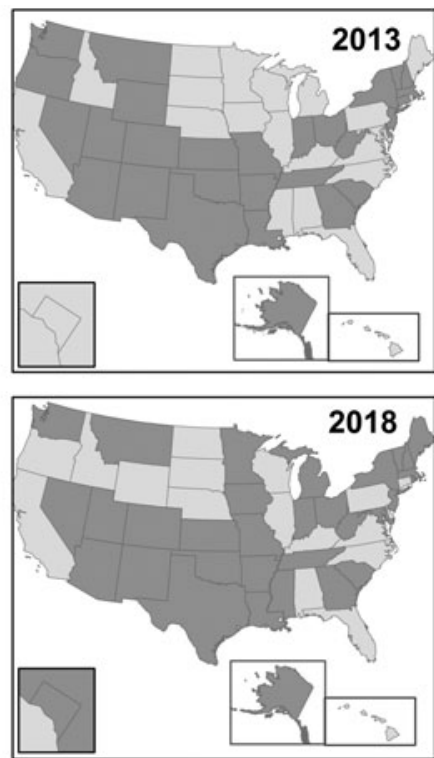

Limit use of restrictive equipment for holding infants while awake
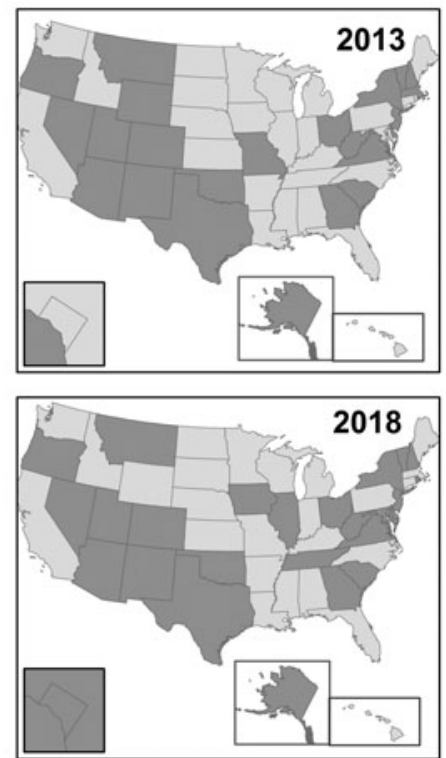

Limit use of restrictive equipment for holding infants while awake

Figure 1. (A) Infant physical activity regulations for child care centers, 2013 and 2018, and (B) infant physical activity regulations for family child care homes, 2013 and 2018.

Some states enacted new regulations requiring ECE providers to use cribs, car seats, and high chairs for their primary purpose. However, based on the wording of these regulations, states may have been motivated by a desire to prevent sleep-related infant deaths. Many state regulations required ECE providers to move infants who have fallen asleep in car seats or other inappropriate sleeping locations to a crib. Sudden infant death syndrome and accidental sleep-related suffocation are common types of sudden unexplained infant deaths (SUID).$^{34}$ In our prior review of state regulations, we attempted to separate and categorize sleep regulations related to obesity versus SUID prevention. ${ }^{17}$ However, we were not able to do so in this review, as not allowing infants to 
sleep in car seats, for example, has both SUID and physical activity benefits.

Similarly, the use of confining equipment, including strollers, swings, and bouncer seats for holding infants while awake, is problematic for a number of reasons. These devices restrict movement and also limit infants' ability to engage freely in their environments, which could impact cognitive, language, and physical (motor) development. ${ }^{7,29,35-37}$ Two recent studies suggest that the use of restrictive equipment is prevalent in ECE settings. ${ }^{33,38}$ However, we found that just over half of states had regulations limiting the use of strollers, swings, and other types of confining equipment. This could be an important area for improvement, as states consider updates to their regulations.

\section{Conclusions}

A number of national organizations have put forth recommendations and standards to promote infant physical activity and reduce inactivity. ${ }^{1-5}$ ECE programs are a primary target, as these settings can be regulated by states. State licensing and administrative regulations for ECE programs have the potential to promote infant physical activity; emerging evidence in slightly older children suggests that new regulations may be an effective way to increase physical activity. ${ }^{28,39}$ Thus, states may consider additional regulations to support and enhance infant physical activity in future updates to regulations.

\section{Acknowledgment}

This study was supported by a grant from the Robert Wood Johnson Foundation (RWJF), Healthy Eating Research \#73391. The content is solely the responsibility of the authors and does not necessarily represent the official views of the RWJF. The funders had no role in the design of the study, data collection and analysis, decision to publish, or preparation of the article.

\section{Author Disclosure Statement}

No competing financial interests exist.

\section{References}

1. Institute of Medicine. Early childhood obesity prevention policies. Secondary Early childhood obesity prevention policies. 2011. www.nationalacademics.org/hmd/Reports/2011/Early-ChildhoodObesity-Prevention/Policies.aspx (Last accessed August 9, 2017).

2. Larson N, Ward DS, Neelon SB, Story M. What role can childcare settings play in obesity prevention? A review of the evidence and call for research efforts. J Am Diet Assoc 2011;111: 1343-1362.

3. Let's Move! Chlid Care. Secondary Let's Move! Chlid Care. 2010. https://letsmove.obamawhitehouse.archives.gov/child-careproviders (Last accessed August 9, 2017).
4. Society of Health and Physical Educators (SHAPE). Active start: A statement of physical activity guidelines for children from birth to age 5. Secondary Active start: A statement of physical activity guidelines for children from birth to age 5. 2009. www.shapeamerica .org/standards/guidelines/activestart.aspx (Last accessed August 9, 2017).

5. American Academy of Pediatrics APHA, National Resource Center for Health and Safety in Child Care and Early Education. Caring for Our Children: National Health and Safety Performance Standards; Guidelines for Early Care and Education Programs, 3rd ed. American Academy of Pediatrics: Elk Grove Village, IL, 2011.

6. Jones RA, Hinkley T, Okely AD, Salmon J. Tracking physical activity and sedentary behavior in childhood: A systematic review. Am J Prev Med 2013;44:651-658.

7. Oudgenoeg-Paz O, Riviere J. Self-locomotion and spatial language and spatial cognition: Insights from typical and atypical development. Front Psychol 2014;5:521.

8. Carson V, Lee EY, Hewitt L, et al. Systematic review of the relationships between physical activity and health indicators in the early years (0-4 years). BMC Public Health 2017;17(Suppl 5):854.

9. Prioreschi A, Micklesfield LK. A scoping review examining physical activity measurement and levels in the first 2 years of life. Child Care Health Dev 2016;42:775-783.

10. Bingham DD, Costa S, Hinkley T, et al. Physical activity during the early years: A systematic review of correlates and determinants. Am J Prev Med 2016;51:384-402.

11. Hesketh KD, Downing KL, Campbell K, et al. Proportion of infants meeting the Australian 24-hour Movement Guidelines for the Early Years: Data from the Melbourne InFANT Program. BMC Public Health 2017;17(Suppl 5):856.

12. Borkhoff CM, Heale LD, Anderson LN, et al. Objectively measured physical activity of young Canadian children using accelerometry. Appl Physiol Nutr Metab 2015;40:1302-1308.

13. United Nations Children's Fund (UNCsF) (UNICEF). The childcare transition innocenti report card. Florence, Italy, 2008.

14. Laughlin L. Who's minding the kids? Child care arrangements: Spring 2011. Current Population Reports, pp.70-135. U.S. Census Bureau, Washington, DC.

15. Slining MM, Neelon SE, Duffey KJ. A review of state regulations to promote infant physical activity in child care. Int J Behav Nutr Phys Act 2014;11:139.

16. U.S. Department of Health and Human Services Administration for Children and Families, Office of Child Care. National Database of Child Care Licensing Regulations. Secondary National Database of Child Care Licensing Regulations. https://childcareta.acf.hhs .gov/licensing (Last accessed August 9, 2017).

17. Benjamin Neelon SE, Duffey K, Slining MM. Regulations to promote healthy sleep practices in child care. Pediatrics 2014;134: $1167-1174$

18. Cradock AL, O’Donnell EM, Benjamin SE, et al. A review of state regulations to promote physical activity and safety on playgrounds in child care centers and family child care homes. J Phys Act Health 2010;7 Suppl 1:S108-S119.

19. Duffey KJ, Slining MM, Benjamin Neelon SE. States lack physical activity policies in child care that are consistent with national recommendations. Child Obes 2014;10:491-500.

20. Kim J, Kaste LM, Fadavi S, Benjamin Neelon SE. Are state child care regulations meeting national oral health and nutritional standards? Pediatr Dent 2012;34:317-324.

21. Benjamin-Neelon SE, Gonzalez-Nahm S, Grossman E, et al. State variations in infant feeding regulations for child care. Pediatrics 2017;140. DOI: 10.1542/peds.2017-2076. 
22. Gonzalez-Nahm S, Grossman ER, Frost N, et al. Media and young minds: Comparing state screen media use regulations for children under 24 months of age in early care and education to a national standard. Matern Child Health J 2018;22:445-453.

23. Grossman ER, Gonzalez-Nahm S, Frost N, Benjamin-Neelon SE. Childcare providers' possession or use of marijuana, tobacco, or alcohol while caring for children: A comparison of US State Regulations. Am J Public Health 2018;108:748-753.

24. Benjamin SE, Taveras EM, Cradock AL, et al. State and regional variation in regulations related to feeding infants in child care. Pediatrics 2009;124:e104-e111.

25. Benjamin Neelon SE, Taveras EM, Ostbye T, Gillman MW. Preventing obesity in infants and toddlers in child care: Results from a pilot randomized controlled trial. Matern Child Health J 2014;18: 1246-1257.

26. Benjamin SE, Cradock A, Walker EM, et al. Obesity prevention in child care: A review of U.S. state regulations. BMC Public Health 2008;8:188.

27. Benjamin Neelon SE, Finkelstein J, Neelon B, Gillman MW. Evaluation of a physical activity regulation for child care in Massachusetts. Child Obes 2017;13:36-43.

28. O'Neill JR, Dowda M, Benjamin Neelon SE, et al. Effects of a new state policy on physical activity practices in child care centers in South Carolina. Am J Public Health 2017;107:144-146.

29. Pin T, Eldridge B, Galea MP. A review of the effects of sleep position, play position, and equipment use on motor development in infants. Dev Med Child Neurol 2007;49:858-867.

30. Dudek-Shriber L, Zelazny S. The effects of prone positioning on the quality and acquisition of developmental milestones in fourmonth-old infants. Pediatr Phys Ther 2007;19:48-55.

31. Kuo YL, Liao HF, Chen PC, et al. The influence of wakeful prone positioning on motor development during the early life. $J$ Dev Behav Pediatr 2008;29:367-376.

32. Hewitt L, Stanley RM, Okely AD. Correlates of tummy time in infants aged 0-12 months old: A systematic review. Infant Behav Dev 2017;49:310-321.
33. Hewitt L, Benjamin-Neelon SE, Carson V, et al. Child care centre adherence to infant physical activity and screen time recommendations in Australia, Canada and the United States: An observational study. Infant Behav Dev 2017;50:88-97.

34. Shapiro-Mendoza CK, Camperlengo L, Ludvigsen R, et al. Classification system for the sudden unexpected infant death case registry and its application. Pediatrics 2014;134:e210-e219.

35. Oudgenoeg-Paz O, Leseman PP, Volman MC. Exploration as a mediator of the relation between the attainment of motor milestones and the development of spatial cognition and spatial language. Dev Psychol 2015;51:1241-1253.

36. Oudgenoeg-Paz O, Volman MC, Leseman PP. First steps into language? Examining the specific longitudinal relations between walking, exploration and linguistic skills. Front Psychol 2016;7: 1458 .

37. Libertus K, Violi DA. Sit to talk: Relation between motor skills and language development in infancy. Front Psychol 2016;7:475.

38. Hallam RA, Bargreen $\mathrm{K}$, Fouts $\mathrm{HN}$, et al. The use of infant confinement equipment in community-based child care centers: An analysis of centers participating in a statewide quality rating and improvement system. Matern Child Health J 2018;22:694701.

39. Wright DR, Kenney EL, Giles CM, et al. Modeling the cost effectiveness of child care policy changes in the U.S. Am J Prev Med 2015;49:135-147.

Address correspondence to:

Sara E. Benjamin-Neelon, PhD, JD Department of Health, Behavior, and Society Johns Hopkins Bloomberg School of Public Health 615 N Wolfe Street, Suite W3041 Baltimore, MD 21205

E-mail: sara.neelon@jhu.edu 